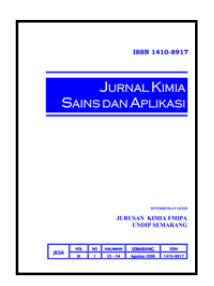

\title{
Pengaruh Pemanasan Pada Proses Pembuatan Ekstrak Kulit Buah Manggis (Garcinia mangostana Linn) terhadap Aktivitas Antimikroba
}

\author{
Dini Kurnia Wisatya ${ }^{a}$, Purbowatiningrum Ria Sarjono ${ }^{a^{*}}$, Nies Suci Mulyani ${ }^{\text {a }}$ \\ a Biochemistry Laboratory, Chemistry Department, Faculty of Sciences and Mathematics, Diponegoro University, Jalan Prof. \\ Soedarto, Tembalang, Semarang 50275 \\ * Corresponding author: pubowatining@live.undip.ac.id
}

Article Info

Keywords:

Antimicrobial, Garcinia mangostana, Paper Discs, KHM

\begin{abstract}
A study on the effect of heating on the production process of mangosteen peel extract (Garcinia mangostana Linn) on antimicrobial activity has been conducted. A heating method was used on the production process of mangosteen peel extract whereas a paper disc method and dry weight method were used in antimicrobial test. Microbes tested were Escherichia coli, Staphylococcus aureus, Candida albicans yeast and Aspergillus niger fungi. Paper disc method was used to identify antimicrobial activity in Escherichia coli bacteria, Staphylococcus aureus, Candida albicans yeast, though the dry weight method was used to recognize antimicrobial activity of Aspergillus niger fungus. Minimum Inhibitory Concentration on paper disc method for bacterial microbe Escherichia coli, Staphylococcus aureus, Candida albicans yeast were $5 \%(\mathrm{w} / \mathrm{v})$, with average inhibit zone of $0.043 \mathrm{~cm}^{2}$, $0.018 \mathrm{~cm}^{2}, 0,013 \mathrm{~cm}^{2}$ respectively. While at Aspergillus niger fungi at concentration $0,5 \%$ $(\mathrm{w} / \mathrm{v})$ with dry weight of 0.06 gram.
\end{abstract}

\section{Abstrak}

Telah dilakukan penelitian tentang pengaruh pemanasan pada proses pembuatan ekstrak kulit buah manggis (Garcinia mangostana Linn) terhadap aktivitas antimikroba. Metode yang digunakan adalah metode pemanasan pada proses pembuatan ekstrak kulit buah manggis sedangkan metode cakram kertas dan metode berat kering digunakan pada uji antimikroba. Mikroba yang diuji menggunakan, bakteri Escherichia coli, Staphylococcus aureus, khamir Candida albicans, dan jamur Aspergillus niger. Metode cakram kertas untuk mengidentifikasi aktivitas antimikroba pada bakteri Escherichia coli, Staphylococcus aureus, khamir Candida albicans, sedangkan metode berat kering digunakan untuk identifikasi aktivitas antimikroba dari jamur Aspergillus niger. Konsentrasi Hambat Minimum pada metode cakram kertas pada mikroba bakteri Escherichia coli, Staphylococcus aureus, khamir Candida albicans yaitu $5 \%(\mathrm{w} / \mathrm{v})$, dengan rata-rata luas zona hambat masing-masing $0,043 \mathrm{~cm}^{2}, 0,018 \mathrm{~cm}^{2}, 0,013 \mathrm{~cm}^{2}$. Sedangkan pada jamur Aspergillus niger pada konsentrasi 0,5\% (w/v), dengan berat kering 0,06 gram.

\section{Pendahuluan}

Manggis (Garcinia mangostana L) merupakan pohon yang berasal dari hutan tropis yang teduh di kawasan Asia Tenggara, yaitu hutan belantara Malaysia dan Indonesia. Buah manggis panen pada bulan November hingga bulan Maret, setiap panen manggis dapat menghasilkan buah hingga 20 ton atau 200.000 buah (untuk lahan 1 hektar). Kulit buah manggis merupakan komponen terbesar dari buah manggis sebesar $60,82 \%$ dari berat buah utuh, sedangkan daging buahnya sendiri hanya 35,51\% dari buah utuhnya [1]. Manggis mempunyai berat buah utuh rata-rata 107,37 gram, 
sehingga 1 buah manggis mempunyai berat kulit buah rata-rata sebesar 65,52 gram.

Banyak kulit buah manggis yang terbuang sia-sia setiap panen dan akan menjadi sampah, sedangkan manfaat dari kulit buah manggis sangat banyak , diantaranya dapat dijadikan sebagai pewarna alami dan bahan baku obat-obatan yang dibuat dalam bentuk kapsul untuk suplemen diet, antioksidan [2], antikanker [3], bahan pembuat kosmetik [4], mencegah terjadinya artritis dan alzheimer (merupakan salah satu penyakit disfungsi otak) yang disebabkan oleh peradangan, selain itu juga antioksidannya bahkan melebihi vitamin $\mathrm{C}$ dan E serta antifungi [5].

Penelitian lain yang telah dilakukan yaitu terhadap ekstrak kulit buah manggis dengan pelarut $n$-heksan dan etil asetat ternyata mampu menghambat pertumbuhan bakteri Shigella flexneri, Salmonella typhi dan Escherichia coli. Dengan Konsentrasi hambat minimum (KHM) isolat mangostin berturut-turut 4,6 , $4 \mathrm{mg}[6]$.

Dalam penelitian ini digunakan mikroba berupa; Bakteri Escherichia coli, Staphylococcus aureus, Khamir Candida albicans, Fungi Aspergilus niger. Digunakan mikroba tersebut karena mikroba diatas merupakan mikroba patogen, yang dapat merusak ataupun dapat menyebabkan penyakit baik bagi makhluk hidup.

Untuk mengetahui kemampuan suatu senyawa sebagai pengawet maka perlu dilakukan pengujian antimikroba terhadap bahan alam tersebut dalam menghambat pertumbuhan mikroorganisme pembusuk, dengan menggunakan metode yang paling umum yaitu metode cakram kertas dan metode perforasi [7] dan juga metode berat kering, selain itu juga dilakukan uji fitokimia.

Penelitian ini bertujuan untuk memperoleh Konsentrasi Hambat Minimum (KHM) dari ekstrak kulit buah manggis (Garcinia mangostana Linn) terhadap bakteri Escherichia coli, Staphylococcus aureus, Khamir Candida albicans, dan Fungi Aspergilus niger dengan menggunakan metode cakram kertas dan metode perforasi dan berat kering.

\section{Bahan dan Metode}

\section{Alat dan Bahan}

Peralatan yang digunakan dalam penelitian ini adalah inkubator (Memmert), penggaris, mikropipet, shaker, autoklaf klinis (prestide medical series 2100), cawan petri, sentrifuge, jarum ose, alumunium foil, lemari es, speader, kapas, botol semprot, blender (Panalux), neraca analitik (Kern 870), kain saring, oven, gelas beaker, erlenmeyer, pengaduk, kompor listrik, gelas ukur (pyrex)

Bahan yang digunakan dalam penelitian ini adalah kulit buah manggis, bakteri Escherichia coli, Staphylococcus aureus, Khamir Candida albicans, dan Fungi Aspergilus niger, Nutrient Broth (NB), Nutrient Agar (NA), Saboraud Dextrose Agar (SDA), Saboraud
Dextrose Broth (SDB), Ekstrak Tauge, Spirtus, Alkohol $70 \%$ dan akuades.

\section{Pembuatan Ekstrak}

\section{Variasi Suhu}

Kulit buah manggis (bagian lunak) diblender hingga menjadi serbuk basah, dari serbuk dilarutkan dengan menggunakan air dengan perbandingan 2:1 (serbuk kulit manggis:air), dan dipanaskan pada suhu $37^{\circ} \mathrm{C}$ selama 5 menit. Setelah 5 menit dilakukan penyaringan.

Perlakuan ini dilakukan pada variasi suhu 40; 45; $50 ; 55 ; 60 ; 65 ; 70 ; 75 ; 80 ; 85 ; 90 ; 95\left({ }^{\circ} \mathrm{C}\right)$. Dari hasil perlakuan ini selanjutnya dilakukan uji antimikroba untuk menghasilkan data suhu optimum yang akan digunakan pada pembuatan ekstrak dengan variasi konsentrasi.

\section{Variasi Konsentrasi}

Kulit buah manggis (bagian lunak) diblender hingga menjadi serbuk basah, dari serbuk diambil $\mathrm{W}$ gram (pada tabel di bawah) yang selanjutnya ditambahkan air sebanyak $10 \mathrm{~mL}$, dan dipanaskan pada suhu optimum selama 5 menit. Setelah 5 menit dilakukan penyaringan. Perlakuan ini dilakukan pada variasi konsentrasi sesuai tabel 1 berikut:

Tabel 1. Kondisi perlakuan

\begin{tabular}{ccc}
\hline $\begin{array}{c}\text { Variasi } \\
\text { Konsentrasi (\%) }\end{array}$ & $\begin{array}{c}\text { Berat (W) } \\
(\text { gram })\end{array}$ & $\begin{array}{c}\text { Volume }(\mathrm{V}) \\
(\mathrm{mL})\end{array}$ \\
\hline 0,1 & 0,01 & $10 \mathrm{~mL}$ \\
0,5 & 0,05 & $10 \mathrm{~mL}$ \\
1 & 0,1 & $10 \mathrm{~mL}$ \\
2,5 & 0,25 & $10 \mathrm{~mL}$ \\
5 & 0,5 & $10 \mathrm{~mL}$ \\
10 & 1 & $10 \mathrm{~mL}$ \\
20 & 2 & $10 \mathrm{~mL}$ \\
40 & 4 & $10 \mathrm{~mL}$ \\
50 & 5 & $10 \mathrm{~mL}$ \\
60 & 6 & $10 \mathrm{~mL}$ \\
80 & 8 & $10 \mathrm{~mL}$ \\
\hline
\end{tabular}

Dari hasil percobaan ini selanjutnya akan dilakukan uji antimikroba untuk menghasilkan konsentrasi hambat minimum.

\section{Sterilisasi Alat dan Bahan}

Erlenmeyer, penjepit, petri dish, media NB, media $N A$, dan seluruh alat yang akan digunakan disterilisasi di dalam autoklaf, selama 20 menit dengan tekanan sebesar $1 \mathrm{~atm}$ dan suhu $121^{\circ} \mathrm{C}$ setelah sebelumnya dicuci bersih, dikeringkan dan dibungkus dengan kertas [7].

\section{Regenerasi Bakteri}

Dari biakan stok agar miring diambil satu mata ose bakteri Escherichia coli diinokulasikan ke erlenmeyer yang berisi kurang lebih $100 \mathrm{~mL}$ media Nutrien Broth (NB) steril. Inokulum Escherichia coli diinkubasi di dalam inkubasi bergoyang (shaker) selama 24 jam pada suhu 
ruang [8]. Dari hasil regenerasi ini akan diperoleh E. coli dengan umur yang lebih muda dan mempunyai keaktifan yang baik. Perlakuan yang sama pada bakteri Staphylococcus aureus

\section{Regenerasi Khamir}

Dari biakan stok agar miring diambil satu mata ose khamir Candida albicans diinokulasikan ke erlenmeyer yang berisi kurang lebih $100 \mathrm{~mL}$ media SDB (Sabouraud Dextrose Broth) steril. Inokulum Candida albicans diinkubasi di dalam inkubasi bergoyang (shaker) selama 24 jam pada suhu ruang [8, 9]. Dari hasil regenerasi ini akan diperoleh Khamir Candida albicans dengan umur yang lebih muda dan mempunyai keaktifan yang baik.

\section{Regenerasi Jamur}

Dari biakan stok agar miring diambil satu mata ose jamur Aspergillus niger diinokulasikan ke erlenmeyer yang berisi kurang lebih $100 \mathrm{~mL}$ media tauge steril. Inokulum Aspergillus niger diinkubasi di dalam inkubasi bergoyang (shaker) selama 72 jam pada suhu ruang [10]. Dari hasil regenerasi ini akan diperoleh Jamur A. niger dengan umur yang lebih muda dan mempunyai keaktifan yang baik.

\section{Pengujian Antimikroba dengan Metode Cakram Kertas dengan Variasi Suhu}

Hasil ekstrak pada tahap pembuatan ekstrak variasi suhu, diuji pada suspensi bakteri Escherichia coli, Staphylococcus aureus, dan khamir Candida albicans, dengan cara, cawan petri yang berisi media Nutrient Agar yang telah disterilkan dan memadat masing - masing diinokulasikan Escherichia coli, Staphylococcus aureus, dan Candida albicans sebanyak $50 \mu \mathrm{L}$ dan diratakan menggunakan spreader. Pada permukaan masingmasing inokulum tersebut diletakkan cakram kertas berdiameter $\pm 6 \mathrm{~mm}$ yang telah dilewatkan di atas lampu Bunsen (aseptik), yang dicelupkan dalam larutan ekstrak kulit buah manggis dengan pemanasan $37^{\circ} \mathrm{C}$ pada masing-masing inokulum. Inokulum tersebut diinkubasi pada suhu $37^{\circ} \mathrm{C}$ selama 24 jam. Zona bening yang berbentuk di sekeliling cakram diukur menggunakan penggaris [11, 12].

Perlakuan tersebut di atas juga dilakukan pada pemanasan pada suhu 40, 45, 50, 55, 60, 65, 70, 75, 80, $85,90\left({ }^{\circ} \mathrm{C}\right)$. Dari hasil diatas diperoleh suhu optimum dengan metode cakram kertas yang digunakan sebagai acuan dalam tahap selanjutnya.

\section{Pengujian Antimikroba dengan Metode Cakram Kertas dengan Variasi Konsentrasi}

Hasil ekstrak pada tahap pembuatan ekstrak variasi konsentrasi, diuji pada suspensi bakteri Escherichia coli, Staphylococcus aureus, dan khamir Candida albicans, dengan cara; cawan petri yang berisi media Nutrient Agar yang telah disterilkan dan memadat, masing-masing diinokulasikan Escherichia coli, Staphylococcus aureus, dan Candida albicans sebanyak $50 \mu \mathrm{L}$ dan diratakan menggunakan spreader. Pada permukaan masingmasing inokulum tersebut diletakkan cakram kertas berdiameter $\pm 6 \mathrm{~mm}$ yang telah dilewatkan di atas lampu Bunsen (aseptik), yang dicelupkan dalam larutan ekstrak kulit buah manggis pada konsentrasi $80 \%$ pada masing-masing inokulum. Inokulum tersebut diinkubasi pada suhu $37^{\circ} \mathrm{C}$ selama 24 jam. Zona bening yang berbentuk di sekeliling cakram diukur menggunakan penggaris $[11,12]$.

Perlakuan tersebut di atas juga dilakukan pemanasan pada konsentrasi $60 ; 40 ; 50 ; 20 ; 10 ; 5 ; 2,5$; $1 ; 0,5 ; 0,1(\%)(\mathrm{w} / \mathrm{v})$.

\section{Pengujian Antimikroba dengan Metode Berat Kering} dengan Variasi Suhu

Hasil regenerasi jamur A. niger sebanyak $50 \mu \mathrm{L}$ diinokulasikan pada media ekstrak tauge 100mL steril, dari inokulum tersebut ditambahkan ekstrak kulit buah manggis sebanyak $50 \mu \mathrm{L}$ suhu $37^{\circ} \mathrm{C}$ (hasil ekstrak pada tahap pembuatan ekstrak variasi suhu), kemudian dilakukan inkubasi bergoyang (Shaker) selama 72 jam, pada suhu ruang. Hasil shaker disaring menggunakan kertas saring, dan dilakukan pengeringan menggunakan oven pada suhu $100^{\circ} \mathrm{C}$ hingga mencapai berat kering yang stabil, sehingga dihasilkan berat dari jamur Aspergillus niger.

Perlakuan tersebut diatas juga dilakukan pemanasan pada suhu 40, 45, 50, 55, 60, 65, 70, 75, 80, $85,90\left({ }^{\circ} \mathrm{C}\right)$.

\section{Pengujian Antimikroba dengan Metode Berat Kering} dengan Variasi Konsentrasi

Hasil regenerasi jamur $A$. niger sebanyak $50 \mu \mathrm{L}$ diinokulasikan pada media ekstrak tauge $100 \mathrm{~mL}$ steril, dari inokulum tersebut ditambahkan ekstrak kulit buah manggis sebanyak $50 \mu \mathrm{L}$ dengan konsentrasi 80\% (hasil ekstrak pada tahap pembuatan ekstrak variasi konsentrasi), kemudian dilakukan inkubasi bergoyang (Shaker) selama 72 jam, pada suhu ruang. Hasil shaker disaring dilakukan penyaringan menggunakan kertas saring, dan dilakukan pengeringan menggunakan oven pada suhu $100^{\circ} \mathrm{C}$ hingga mencapai berat kering yang stabil, sehingga dihasilkan berat dari jamur Aspergillus niger.

Perlakuan tersebut diatas juga dilakukan pada variasi konsentrasi $60 ; 40 ; 50 ; 20 ; 10 ; 5 ; 2,5 ; 1 ; 0,5 ; 0,1$ (\%) (w/v).

\section{Hasil dan Pembahasan}

Pada penelitian antimikroba ini, sampel yang digunakan adalah kulit buah manggis (Garcinia manggostana Linn). Tujuan dari penelitian ini untuk memperoleh Konsentrasi Hambat Minimum (KHM) dari ekstrak kulit buah manggis, dengan menggunakan mikroba uji bakteri E. coli, S. aureus, dan khamir $C$. albicans, Jamur A. niger, yang merupakan mikroba patogen. Dari penelitian yang telah dilakukan diperoleh hasil pada masing-masing tahap, sebagai berikut;

\section{Pembuatan Ekstrak Kulit Buah Manggis (Garcinia manggostana Linn)}

Pada proses pembuatan ekstrak kulit buah manggis digunakan kulit manggis bagian dalam (lunak), bagian yang mengandung banyak zat aktif [2] dan air sebagai 
pelarut, karena air tidak mempunyai kemampuan antimikroba, selain itu pelarut air paling banyak digunakan, aman, murah dan mudah didapat, serta dapat juga diaplikasikan dalam skala rumah tangga.

Dalam pembuatan ekstrak kulit buah manggis dilakukan dengan pemanasan, fungsi dari pemanasan untuk mendapatkan senyawa aktif yang terdapat dalam kulit buah manggis, karena dengan pemanasan jaringan sel pada kulit manggis akan merenggang, akibatnya semakin banyak pula isi sel yang ke luar (termasuk metabolit sekunder). Jika suhunya terlalu tinggi, senyawa aktif yang keluar dari sela-sela sel akan rusak.

Pemanasan ekstrak kulit buah manggis dilakukan pada variasi suhu $37^{\circ} \mathrm{C}-95^{\circ} \mathrm{C}$, yang selanjutnya akan dilakukan uji antimikroba terhadap bakteri Escherichia coli, Staphylococcus aureus, khamir Candida albicans, jamur Aspergilus niger, untuk menghasilkan kondisi optimum dalam melakukan pemanasan pada ekstraksi kulit buah manggis.

Uji Pengaruh Pemanasan Ekstrak terhadap aktivitas antibakteri

Hasil dari penelitian ini yang menunjukkan aktivitas terbesar pada ekstrak kulit buah manggis dengan variasi suhu, yaitu pada suhu $70^{\circ} \mathrm{C}$, sehingga suhu yang digunakan dalam variasi konsentrasi pada suhu $70^{\circ} \mathrm{C}$. Dari hasil uji antimikroba terhadap variasi suhu dihasilkan luas zona hambat pada suhu $70^{\circ} \mathrm{C}$ dari bakteri Escherichia coli, Staphylococcus aureus, Khamir Candida albicans, berturut-turut $1,84 \mathrm{~cm}^{2}, 4,41 \mathrm{~cm}^{2}$, $0,79 \mathrm{~cm}^{2}$ sedangkan pada Jamur $A$. niger mempunyai selisih berat kering sebesar 0,02 gram.

Uji Antimikroba pada Ekstrak Kulit Buah Manggis dengan Variasi Konsentrasi

Ekstrak kulit buah manggis, disiapkan dengan melakukan pemanasan pada suhu $70^{\circ} \mathrm{C}$ dengan variasi konsentrasi $0,1 \%-80 \%(\mathrm{w} / \mathrm{v})$. Metode yang digunakan adalah metode cakram kertas (untuk antibakteri dan antikhamir) dan berat kering (antijamur).

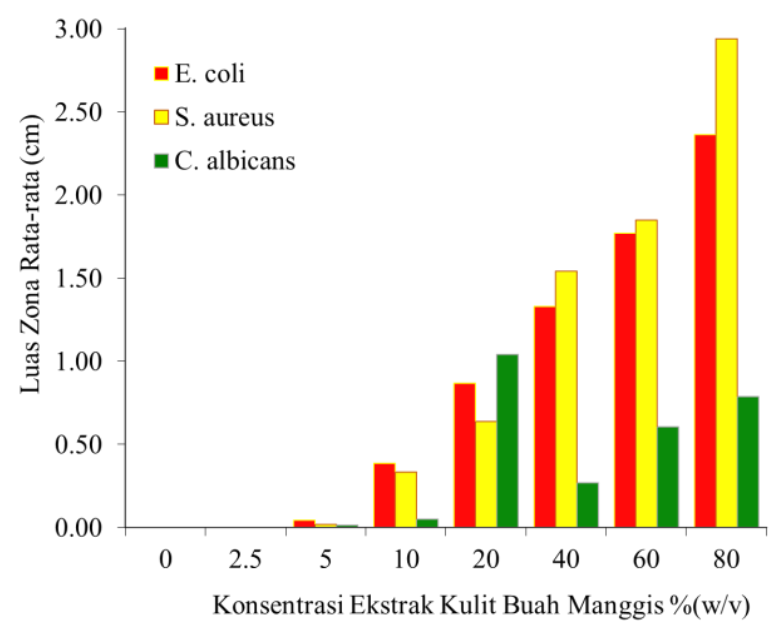

Gambar 1. Grafik hubungan antara konsentrasi ekstrak kulit buah manggis dengan luas zona hambat dengan metode cakram kertas

Berdasarkan gambar 1 dapat diamati pada bakteri $E$. coli, S. aureus, menunjukkan grafik eksponensial yang artinya semakin besar konsentrasi maka daerah hambatnya semakin besar, karena semakin besar konsentrasi maka senyawa aktif yang terkandung dalam ekstrak akan semakin banyak [8]. Namun pada khamir C. albicans, menunjukkan adanya hasil yang berbeda, yaitu pada konsentrasi $40 \%$ mengalami penurunan luas daerah hambat dibandingkan pada konsentrasi $20 \%$, hal ini dapat terjadi karena pada volume yang sama, konsentrasi $20 \%$ mempunyai kepekatan yang lebih kecil dibandingkan dengan kepekatan dikonsentrasi $40 \%-$ $80 \%$, sehingga pergerakan cairan akan semakin cepat, berkurangnya kepekatan maka kecepatan alir suatu cairan akan semakin besar, tetapi dalam waktu inkubasi 24 jam pada konsentrasi $20 \%$ sudah tidak aktif dalam menghambat pertumbuhan mikroba uji, yang di tunjukkan pada gambar 1I pada konsentrasi $20 \%$ mempunyai zona hambat yang besar, tetapi dengan inkubasi 24 jam di tengah zona hambat ditumbuhi mikroba uji (Candida albicans), yang menandakan dalam waktu 24 jam pada konsentrasi tersebut tidak efektif lagi dalam penghambatan mikroba. Pada konsentrasi $40 \%-$ $80 \%$ mempunyai zona hambat yang kecil, tetapi dengan inkubasi 24 jam masih aktif dalam menghambat pertumbuhan mikroba, yang ditunjukkan pada zona hambat konsentrasi 40\%-80\% masih bening,

Sedangkan pada jamur Aspergillus niger daerah hambatannya diperoleh dari pengurangan berat kering Aspergillus niger, semakin kecil berat kering Aspergillus niger maka semakin besar hambatannya. Dari hasil penelitian menunjukkan semakin besar konsentrasi semakin besar pula hambatannya, hal ini ditunjukkan dengan berkurangnya berat kering Aspergillus niger.

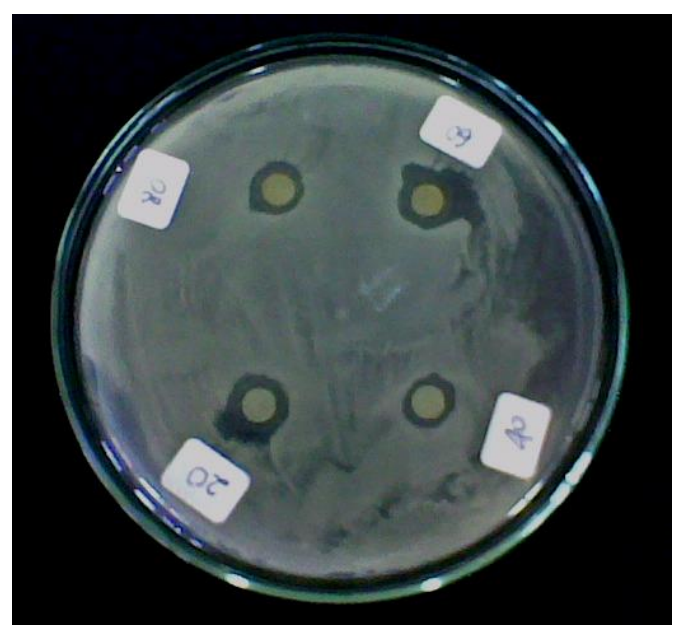

Gambar 2. Zona hambat khamir C. albicans konsentrasi $20 \%-80 \%$ metode cakram kertas 


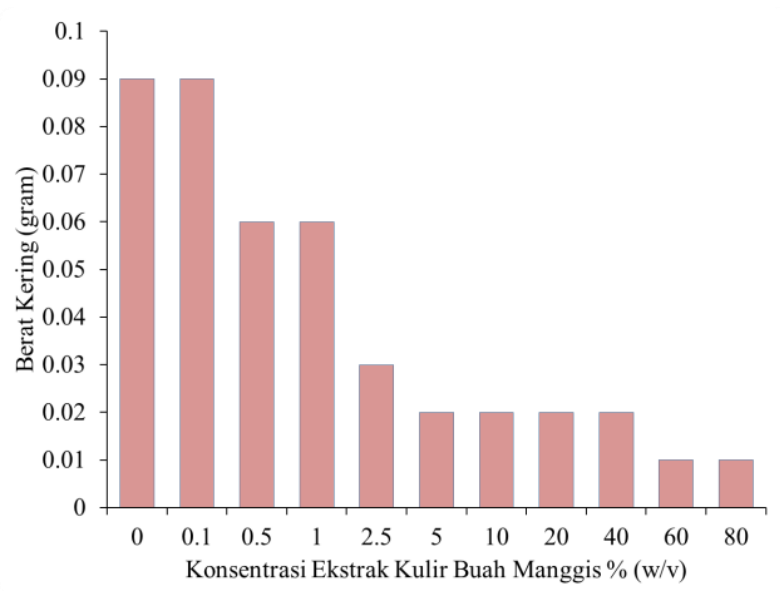

Gambar 3. Grafik hubungan konsentrasi ekstrak kulit buah manggis dengan berat kering pada metode berat kering

\section{Penentuan Konsentrasi Hambatan Minimum (KHM)}

Setelah di peroleh data penghambatan ekstrak kulit buah manggis terhadap pertumbuhan mikroba, maka selanjutnya dapat ditentukan nilai KHM (Konsentrasi Hambat Minimum) ekstrak kulit buah manggis terhadap pertumbuhan mikroba. KHM ditentukan untuk arahan mengawetkan atau menghambat pertumbuhan mikroba. Penentuan KHM ini dilakukan dengan cara menentukan konsentrasi terendah ekstrak kulit buah manggis yang mampu menghambat pertumbuhan mikroba [12]. Sesuai gambar 1, KHM ekstrak kulit buah manggis dengan menggunakan metode cakram kertas terhadap mikroba bakteri $E$. coli, S. aureus, khamir $C$. albicans, adalah 5\%, dengan rata-rata luas zona hambat masing-masing $0,043 \mathrm{~cm}^{2}, 0,018 \mathrm{~cm}^{2}, 0,013 \mathrm{~cm}^{2}$. Sedangkan pada jamur Aspergillus niger pada konsentrasi $0,5 \%(\mathrm{w} / \mathrm{v})$, dengan berat kering 0,06 gram.

\section{Kesimpulan}

Suhu pemanasan optimum pada proses pembuatan ekstrak yaitu suhu $70^{\circ} \mathrm{C}$, berdasarkan hasil zona hambat terbesar. Konsentrasi hambat minimum (KHM) ekstrak kulit buah manggis terhadap bakteri Escherichia coli, Staphylococcus aureus, khamir Candida albicans, dengan metode cakram kertas yaitu $5 \%(\mathrm{w} / \mathrm{v})$, pada jamur Aspergillus niger 0,5\% (w/v).

\section{Daftar Pustaka}

[1] Rudi Kastaman, Analisis Prospektif Pengembangan Produk Olahan Manggis (Garcinia mangostana) Dalam Upaya Meningkatkan Pendapatan Petani (Studi Kasus Di Kecamatan Puspahiang Kabupaten Tasikmalaya), Jurnal Agrikultura, 18, 1, (2007)

[2] Warid Ali Qosim, Kulit Buah Manggis Sebagai Antioksidan, , in, Lembaga Penelitian Masyarakat, Universitas Padjadjaran, Bandung, 2007.

[3] Sunit Suksamrarn, Orapin Komutiban, Piniti Ratananukul, Nitirat Chimnoi, Nattapat Lartpornmatulee, Apichart Suksamrarn, Cytotoxic Prenylated Xanthones from the Young Fruit of Garcinia mangostana, Chemical and Pharmaceutical Bulletin, 54, 3, (2006) 301-305 http://dx.doi.org/10.1248/cpb.54.301
[4] Anthony C. Dweck, A review of Mangosteen (Garcinia mangostana) Linn., in: Personal Care Magazine, 2004, pp. 15-18.

[5] Wilawan Mahabusarakam, Pichaet Wiriyachitra, Saowaluk Phongpaichit, Antimicrobial activities of chemical constituents from Garcinia mangostana Linn, Journal of the Science Society of Thailand, 12, 4, (1986) 239-242

[6] Risma Marisi Tambunan, Soediro Soetarno, Elin Yulinah Sukandar, Telaah Kandungan Kimia dan Aktivitas Antimikroba Kulit Buah Manggis (Garcinia Mangostana L., Guttiferae), in: Sekolah Farmasi, Institut Teknologi Bandung, Bandung, 1998.

[7] Michael J Pelczar, ECS Chan, Dasar-dasar mikrobiologi, Universitas Indonesia Press, Jakarta, 1988.

[8] M Hudayanti, Aktivitas Antibakteri Rimpang Temulawak (Curcuma xanthorrihza Roxb.), in: Jurusan Kimia, Institut Pertanian Bogor, Bogor, 2004 .

[9] Lexa G. Matasyoh, Josphat C. Matasyoh, Francis N. Wachira, Miriam G. Kinyua, Anne W. Thairu Muigai, Titus K. Mukiama, Chemical composition and antimicrobial activity of the essential oil of Ocimum gratissimum L. growing in Eastern Kenya, African Journal of Biotechnology, 6, 6, (2007) 760-765

[10] Uluk Suharsi Putra, Uji Kemampuan Aspergilus niger 6088 IFO 6341 Dalam Mengubah Polisakarida pada Kertas HVS dan Buram Bekas Menjadi Asam Sitrat, in: Jurusan Kimia, Universitas Diponegoro, Semarang, 2007.

[11] Geo F. Brooks, Karen C. Carroll, Janet S. Butel, Stephen A. Morse, Medical Microbiology, 24 ed., McGraw-Hill Education, 2007.

[12] Satish Gupte, Mikrobiologi Dasar, 3 ed., Binarupa Aksara, Jakarta, 1990. 